\title{
SLOWED MOTION ANALYSIS OF SOUND PRODUCTION IN THE GRASSHOPPER ARPHIA SULPHUREA (ACRIDIDAE: OEDIPODINAE)
}

\author{
By Robert B. WILley
}

The University of Illinois at Chicago Circle, Biological Sciences, P.O. Box 4348, Chicago, IL 6068o;

and the Rocky Mountain Biological Laboratory, Crested Butte, Colorado 81224

From the time of the classic studies by Pierce (1948) and Pasquinelly \& Busnel (I955), there have been many attempts to slow the movement of insects visually so that the sounds they produce can be analyzed biomechanically. Usually these efforts have been directed towards "elytral" stridulation (Bailey, 1970; Bailey \& Broughton, 1970; Morris \& Pipher, 1972) by the use of photographic stroboscopy and oscillography of potentials from electrodes or sensors on the moving parts or in the muscles governing the movements. Also the Hall-effect has been used to plot oscillographically the movements and acoustic signals simultaneously. This has been effected in an insect as small as Chorthippus mollis by means of permanent magnets attached to the moving femur, which in turn produces a changing voltage in a Hall-generator fixed on the back of the insect between the wings (Elsner, 1970, 1974a). Miniature magnetometers of this type have been used in human vocalization movements also (Hixon, I97I). Other workers have reported routine use of television tape systems with simultaneous sound recording and/or sound visualization (review: Wussow et al., 1974).

All of the methods so far mentioned have disadvantages. I) It is difficult to adjust a stroboscope if motions are non-cyclical, very brief in duration or variable in frequency or velocity. 2) Electrodes and magnetic sensors may restrict or disturb normal behavior of small organisms. Also, simultaneous recording of both femora in motion using the Hall-effect apparatus has not proved feasible (Elsner, 1974a). 3) The nature of the television trace mechanism causes a time delay distortion between the upper and lower portions of the picture when the tape is stopped for analysis. A single video field represents more than $16 \mathrm{msec}$ which is unsuitable for analysis of motions taking less than 50 msec to complete (Steinberg \& Willey, 1974; Wussow et al., 1974). However, for gross motion studies, the television tape system is the least expensive and most useful of all compound methods. 
An alternative method, ptenocinematography, ${ }^{1}$ is capable of fine resolution of visual-acoustical signals. Walker et al. (1970) showed that motion pictures of actions and the oscillograms of sounds produced by those acts can be synchronized by using a two-lens system of an ultra-high-speed motion picture camera to show the generation of stridulations by tree crickets (Oecanthinae). I wish to present here an independently developed method which uses a similar principle for analysis of femoro-tegminal stridulations of the grasshopper Arphia sulphurea. The basic behavior patterns of $A$. sulphurea have been described in detail by Otte (1970). I have published an abstract of the methods (Willey, I97I).

\section{Materials ANd Methods}

Arphia sulphurea was reared in captivity from eggs produced by females collected in an abandoned gravel and limestone quarry in the village of Oconomowoc Lake, Waukesha County, Wisconsin. Figure I diagrams the arrangement of the photorecording equip-

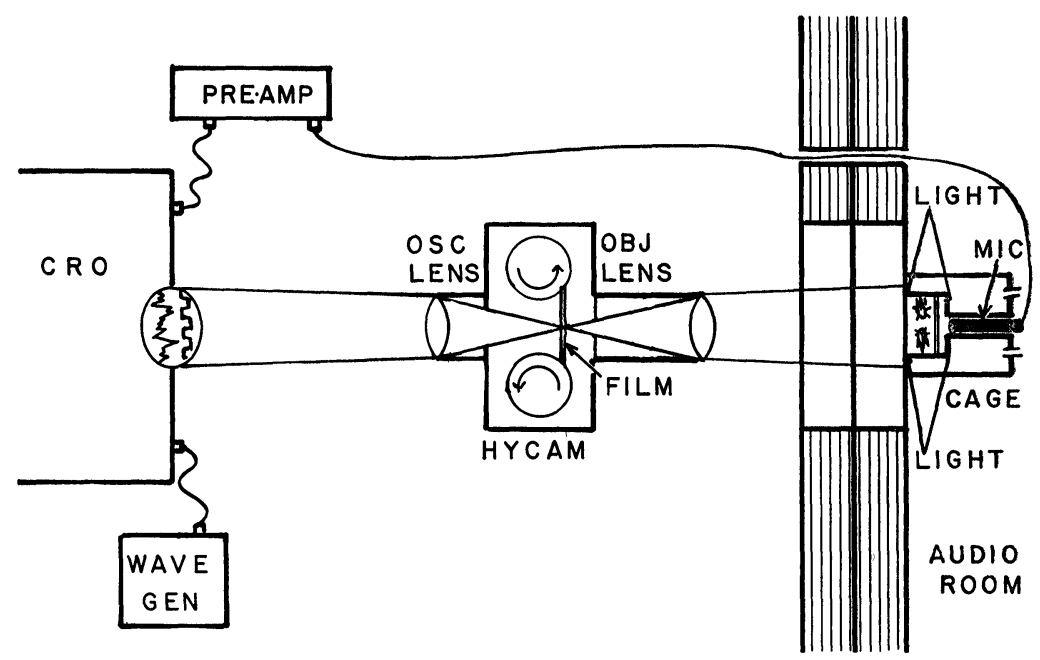

Fig. 1. Schema of equipment arranged for ptenocinematography, top view. $\mathrm{CRO}=$ cathode-ray oscilloscope, OSC $=$ oscillo-lens, $\mathrm{MIC}=$ microphone. Three movie lights were used in addition to the two on either side of the cage, one was attached to the HYCAM above the objective lens.

\footnotetext{
${ }^{1}$ Pteno- (derived from the Greek term for rapid, high velocity), a prefix to be preferred to the awkward "ultra-high-speed motion photography" and other phrases.
} 
ment. The basic principle is the superposition of images from two lens systems, one from the moving specimen and one from an oscillographic trace, on the same film frame as it passes the lens openings. The insects were placed in a water-cooled cage (Fig. 2) against the observation window within a double-walled audiometric room (Industrial Acoustics Corporation). The camera (HYCAM, Red Lake Laboratories) was positioned outside the room on the opposite side of the window. An Angenieux I2:120 mm zoom lens faced the insects and was equipped with a I-diopter enlarging lens. The ultra-high-speed $16 \mathrm{~mm}$ camera is capable of speeds up to I I,000 I $6 \mathrm{~mm}$ pictures per second, but only 800 pps was used in the present study. An 8 -sided revolving prism coupled with a I/2.5 shutter is driven by the film advance mechanism. The prism and shutter are in the light path of the front lens only, and this system imposes a minimum aperture of $\mathrm{F} 4.2$ on the objective. The rear lens (Pentax, F. I.8, automatic) which faces the oscilloscope is inserted into the through-the-lens viewing aperture in the camera back. A two-way prism directs the oscillographic image through the back of the film onto the emulsion. (Film with minimum antihalation backing is desirable, q. v.)

The Tektronix 502-A oscilloscope (CRO) has a dual-beam cathode-ray tube (CRT) with a phosphor coating ( $\mathrm{P}_{\text {II }}$ ) which has the least persistence, greatest resolution and greatest photosensitivity ratio for the film speeds used. The trace is viewed on the CRT as a standing wave with only vertical amplification, and the advancing film, moving horizontally in the same direction as a normal oscillotrace, acts as that in a kymograph camera. It is possible to burn the CRT phosphor when the screen is on full intensity, therefore full intensity is used only for the few seconds of filming. The calibrating grid should be removed from the screen for filming. A light-tight sleeve connects the oscillo-lens and the CRT. Beam orientation and focus are important. The upper trace should be inverted so that the normal positive peaks of both traces point to the center of the screen (therefore, the film track) - especially if one wishes to have the traces at the sides of the finished film rather than superimposed over the specimen. A timing trace of $1600 \mathrm{~Hz}$ (later calibrated at $1560 \mathrm{~Hz}$ in the pictures here) was produced by a Precision model E-3 io signal generator using the square-wave mode, its $0.5 \mathrm{~cm}$ displacement was a calibration for the amplitude of the other trace.

The acoustic signals were received by a Sennheiser 404 directional condenser microphone situated directly behind the grid in the water- 


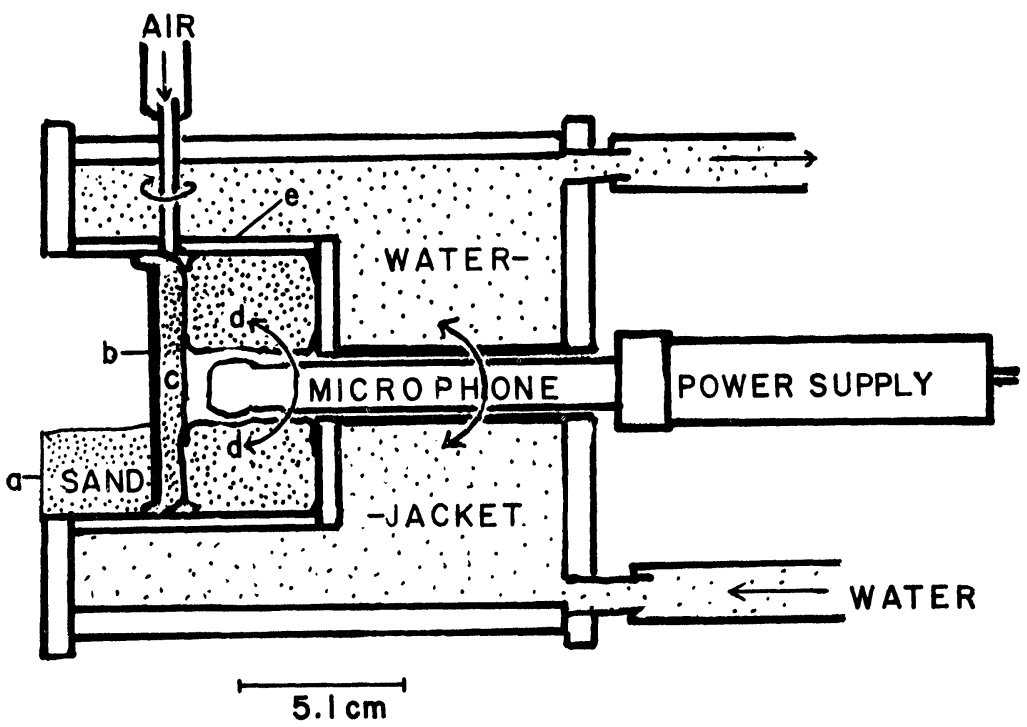

Fig. 2. Schema of the water- and air-cooled observation cage, sagittal section. In practise, the water flow was discontinued during filming, but not more than five minutes at a time. (a) Tape dam, (b) wire mesh screen (nine grids $/ \mathrm{cm}^{2}$ ), (c) plastic foam wind-screening, (d) glass wool acoustical packing, (e) opal plastic cylinder.

cooled cage (Fig. 2). The distance was only 2 or $3 \mathrm{~cm}$ and therefore time delay due to speed of sound in air was negligible. Figure 9 illustrates the maximum calculated delay ( $0.1 \mathrm{msec}$, frame duration of $1.2 \mathrm{msec}$, shutter speed of $0.5 \mathrm{msec}$ ). Electronic delay also can be considered negligible. The microphone was protected from the noise of the air stream in the cage by a glass wool material which effectively dampened the acoustical components of the air stream. This is the same material used in the audiometric room to silence the ventilation system. The microphone, powered by mercury batteries totalling $7.5 \mathrm{~V}$, was connected to the CRO by means of a $20 \mathrm{ft}(6 \mathrm{~m})$ extension cord and Acoustic Designs ADM 667 preamplifier.

The subjects were illuminated by three General Electric Company MG-I movie lights with $500 \mathrm{~W}$ mini-lamps. One light was attached to the camera outside the audiometric room and was used at full intensity for front lighting; the other two lights were used inside the room to side-light the insects (Fig. 2). The inside cylinder of the cage is of white opal plastic to diffuse the incoming side light. 
The side lights were reduced by a rheostat to $60 \%$ intensity for the present experiment because the greater intensity resulted in compulsive phototropism (in the sense of Verheijen, 1958) and a disturbed dorsal light reflex by the insects, effectively inhibiting any social interactions.

Kodak RAR 2485 Instrumentation film (on thin Estar-base) has a reversal exposure index (E. I.) of 1600 and a photosensitivity rating of 10,000 in response to the activated $\mathrm{P}$ II CRT phosphor coating. Eastman-Kodak MS 857 developer minimizes graininess if development is forced only one F-stop (to E. I. 3200), comparing favorably with Tri-X film of 320 E. I. using standard exposures and D-I9 developer. With the present system the correct exposure for the CRT trace was with the oscillo lens open ( F r.8) and CRT beams at full intensity at $0.65 \mathrm{~m}$. For the subjects $\mathrm{I}$ had to open the front lens $\mathrm{I} / 2$ to $2 \mathrm{~F}$-stops over the reading on the calibrated Hycam exposure meter $\left(\right.$ Pentax $\left.\mathrm{I}^{\circ} / 2 \mathrm{I}^{\circ}\right)$.

Angles and displacements of moving organs were analyzed on a Vanguard motion analyzer (model Mr6C), and the tapes were analyzed with a Kay Electric Co. model 675 audiospectrograph (Missilyzer) and a Tektronix model R5030 oscilloscope and C-7O camera. The secondary emission electron photomicrographs of the stridulatory file were produced by a Cambridge scanning electron microscope using standard mounting and gold shadowing techniques.

\section{Results and Analysis}

Arphia sulphurea and $A$. conspersa have five acoustical signals which Otte (1970) and Willey \& Willey (1969) have discussed in detail. Of these, I have filmed the chirps (ordinary stridulation) produced during contra- and ipsesexual courtships and the flutterrasps (femur-shaking with wing-striking) during male-to-male interactions. Only the chirps will be discussed in this paper and are known to be produced by rubbing a ridge on the medial surface of

Fig. 3. Lateral view of Arphia sulphurea showing position of intercalary vein dorsal to the long median vein.

Figs. 4-6. Secondary emission electron photomicrographs of the stridulatory apparatus of $A$. sulphurea male seen in Fig. 3 .

Fig. 4 , oblique view of intercalary vein from $20^{\circ}$ above the surface of the tegmen, arrow points to the basal origin of the vein, $127 \times$.

Fig. 5, lateral view about $19^{\circ}$ from horizontal plane of the tegmen, $100 \times$.

Fig. 6, vertical view of medial surface of the right mesothoracic femur, arrow points to the area of the femoral ridge which contacts the tegminal file, $20 \times$. 

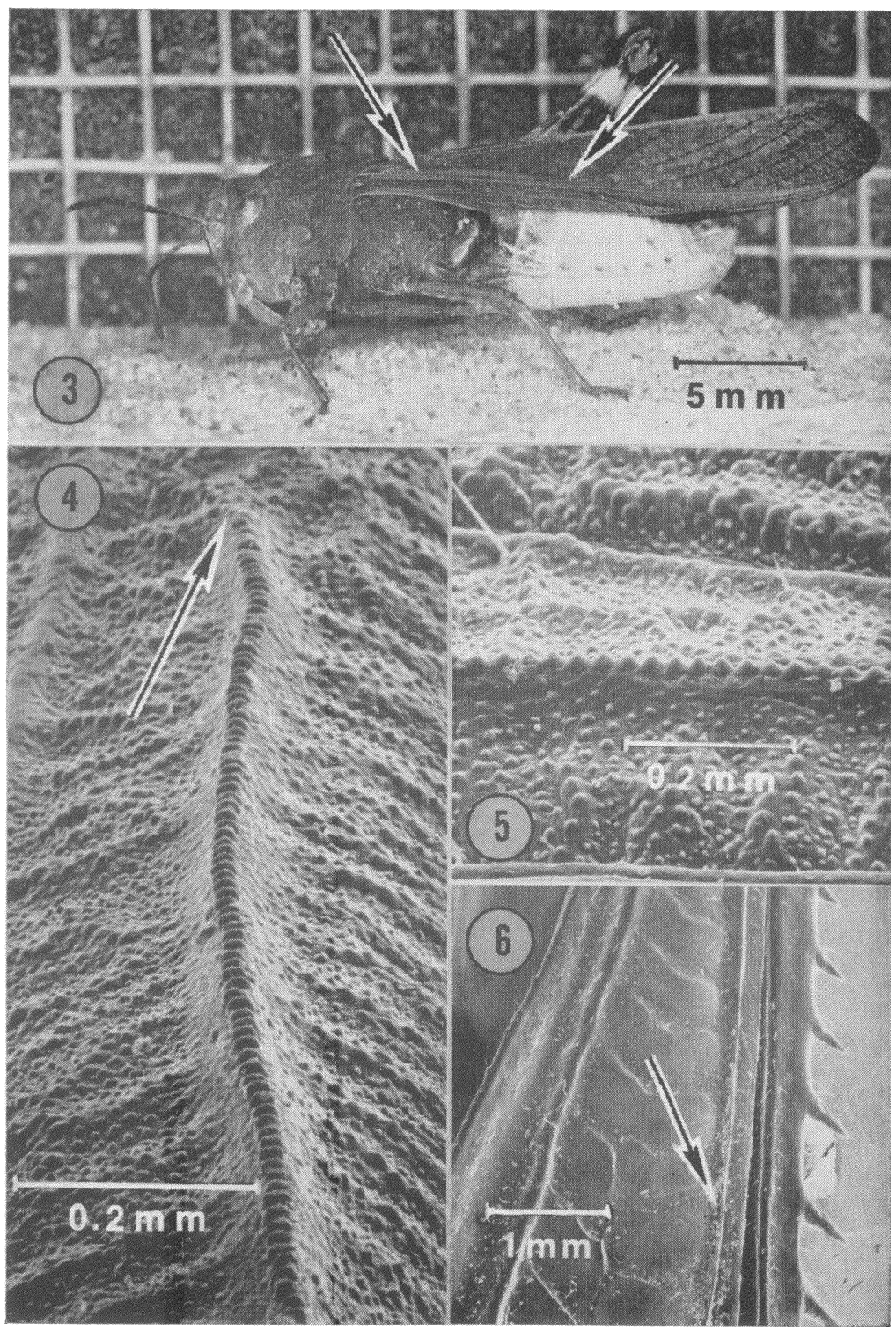
the femur against a row of pegs on a longitudinal intercalary vein of the tegmen or fore-wing. There are $39 \pm 0.88$ (S.E.) pegs per $\mathrm{mm}$ in the file, which averages $6.74 \pm 0.17 \mathrm{~mm}$ in length. ${ }^{2}$ However, the mechanism for production of the flutter-rasp still is unknown.

The acoustical properties of the chirp in $A$. sulphurea have been illustrated by Otte (1970, p. 22) and the present study confirms his report for the usual recording conditions (Fig. $7 \mathrm{~b}$ ). The signal rises in frequency from $2 \mathrm{KHz}$ to $6-8 \mathrm{KHz}$ with a duration of about $50 \mathrm{msec}$. The oscillograms also confirm the frequencies reproduced in the sonagrams. Even tape recordings made under conditions for ptenocinematography are only 50 to $75 \mathrm{msec}$ in duration. Faint peaks sometimes isolated from the higher amplitude signals have been interpreted in the past as sounds made during the upstroke. Comparison of Figs. 7 through 48 will show this interpretation to be partly correct. However, the entire movement recorded by the motion picture camera takes I IO to $\mathrm{I} 4 \mathrm{O} \mathrm{msec}$, during nearly all of which time some sound is produced. It is clear that most of the sound produced on the upstroke is of such low amplitude and frequency that it is not reproduced by the audiospectrograph, nor by an oscilloscope which is regulated to trigger only on the higher amplitude sounds. Whether the upstroke is informationally important is unknown, but doubtful, since it is so variable in duration.

The definitive chirp, however, is made on the downstroke. Figures 8 through 48 make it clear, from measurements and photographs of side and rear views, that the jagged peaked appearance of the chirp is not due to pulsed changes in the velocity of movement, for the femora move rapidly in a single sweep to the resting position. On the other hand, the femora are forced to move in tandem, since the pressure necessary to produce the chirp causes the femoro-tibial joints to overlap the midline and displace one another. It would be interesting to record the first chirps of a young male to determine the ontogeny of this metachronous movement. The net result of the movement of the two femora is to produce pulses of sonic amplification modulated by irregular low amplitude interference as the discrete pulses produced by the two files phase together and then go

\footnotetext{
2The pegs are smaller and more numerous per $\mathrm{mm}$ in the anterior (proximal) part of the file. The mean $=42.2 \pm 0.71$ (S.E.) pegs in the second $\mathrm{mm}$ from the proximal end and $35.8 \pm 0.68$ in the second $\mathrm{mm}$ from the distal end of the file. This difference is highly significant statistically $(\mathrm{t}=6.51, \mathrm{df}=18, \mathrm{p}<<0.005, \mathrm{n}=10$ animals $)$. Further studies are underway to determine the functional significance of this asymmetry.
} 


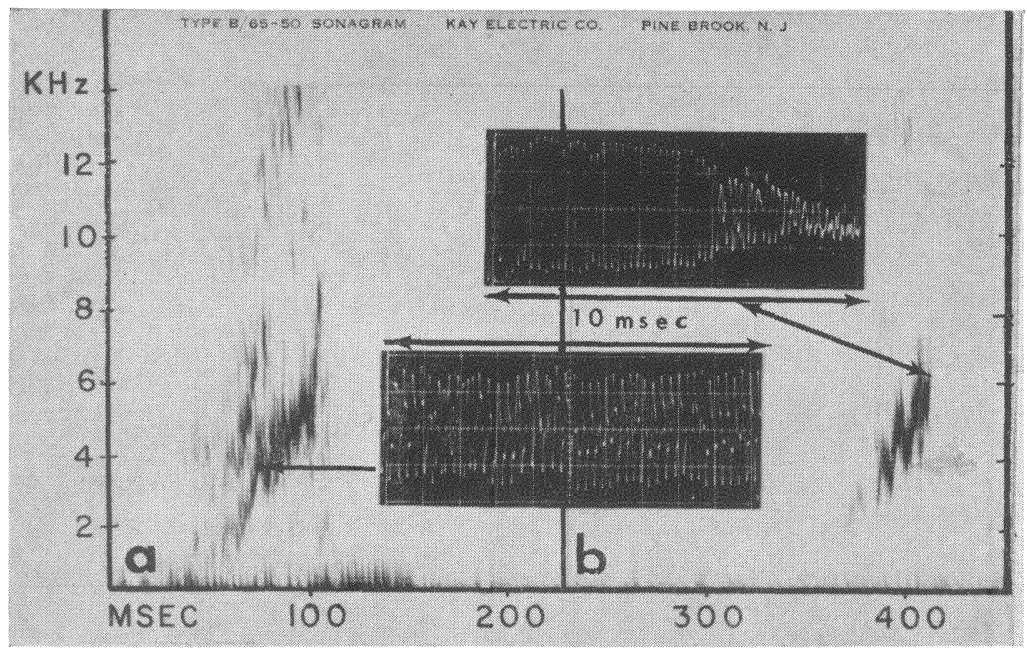

Fig. 7. Audiospectrograms of representative unitary chirps by $A$. sulphurea and the respective oscillograms (inserts). (a) Chirp recorded under ptenocinematographic conditions in water-cooled cage, audiometric room, $35^{\circ} \mathrm{C}$, Sennheiser 404 microphone at $2 \mathrm{~cm}$ with $6 \mathrm{~m}$ extension cord. (b) Chirp recorded under usual conditions of laboratory analysis (microphone $10 \mathrm{~cm}$ from insect, $33^{\circ} \mathrm{C}, 20 \times 30 \mathrm{~cm}$ wire cage in quiet room). Protocol: Audiospectrograms - $0 \mathrm{db}$ input and output levels, $38.1 \mathrm{~cm} / \mathrm{sec}$; record level +2 to $3 \mathrm{VU}, 0.8 \mathrm{sec}$ per revolution; print level $-10 \mathrm{VU}$, filter band width $600 \mathrm{~Hz}$. Oscillograms - vertical $=10 \mathrm{~V}$ per division, horizontal $=$ $1 \mathrm{msec}$. Arrows point to the $10 \mathrm{msec}$ portions of the sonagram from which each oscillogram was derived.

into antiphase, cancelling each other. The sonagrams show that the greatest amplitude (darkest and thickest portion of the trace) always falls in frequency, and the oscillotrace in Figs. 22 and 31 shows this. The faintest portions of the downstroke sonagram are not clear because the period of antiphase is only fractions of a millisecond (Figs. I4, 26, and perhaps 32). The frequencies are variously modulated in other frames between Figs. I 3 and 39. The oscillotrace in Figs. IO to 13 definitely is the result of the movement of the left femur only. However there is some modulation irregularity in the trace from Fig. 39 to Fig. 43, which could be the result of continued unobserved motion of the left femur or some other sound. Figure 43 is typical of the background noise, whereas Fig. 8 is typical of the 40 frames during the upstroke, i.e., wavering non-regular traces of low frequency and amplitude. 


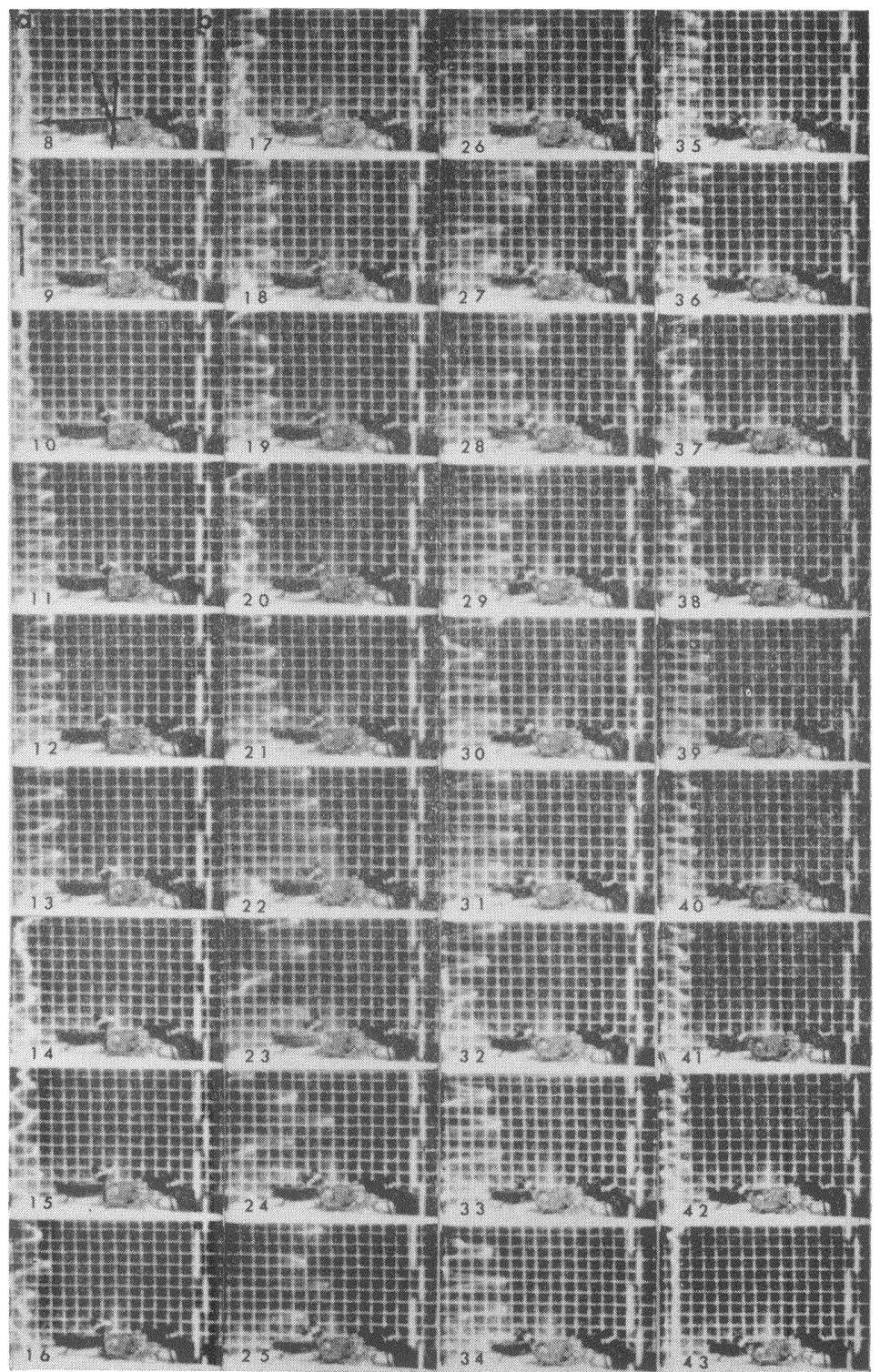


Because the femora often are out of phase and modulate one another, one can not merely count spikes of sound and numbers of pegs on the calculated route of the femur along the stridulatory file. However, the distance travelled during the $10^{\circ}$ change in the angle of the left femur between Figs. IO and 13 (incl.) equals about $0.6 \mathrm{~mm}$ at file level. Since about 22 pegs occur in $0.6 \mathrm{~mm}$ of file and I9 spikes appear in the frames mentioned, each acoustical spike $\cong$ one peg struck. ${ }^{3}$ Such calculations depend on the file being perpendicular to the femoral ridge, and parallel to the direction of stroke. Figures 3 and 4 show the convex curve of the file which would parallel rather accurately the path of the femoral rotation. Of course a one-legged male could solve the problem of interfemoral modulation. Motion pictures of such males in ideal positions for analysis have not yet been produced.

Elsner (1974a) has published an elegant study of stridulations in several gomphocerine species, in which he also is impressed with the

${ }^{3}$ The correct spike count is from the calculated beginning of the synchronized oscillotrace with the image exposure to the end of the calculated synchronization (see Fig. 9). With each frame $=1.2 \mathrm{msec}$, the calculated frequency of 19 spikes per $4.1 \mathrm{msec}$ synchronized oscillotrace corresponds to an average spike frequency of about $4650 \mathrm{~Hz}$. Probably the file was first contacted by the left femur some distance posterior to the file's proximal end. These calculations are at variance by more than $10 \times$ with those of Pierce (1948, p. 250-254) who studied living specimens of $A$. sulphurea in eastern New England. He reported spike frequencies of the "insect at rest" of $360 \mathrm{~Hz}$ with a harmonic frequency of $7900 \mathrm{~Hz}$. It is problematical whether this sound was the chirp or one of the other signals.

Fig. 8 through 43. Ptenocinematographic sequence from the last frame of the upstroke (Fig. 8) and the entire downstroke of a unitary chirp filmed at $800( \pm 10)$ pictures per sec. Entire sequence is graphed in Fig. 44.

Fig. 8, (a) oscillotrace of sound, (b) oscillotrace of $1600 \mathrm{~Hz}$ square wave (later calibrated at 1560), black arrows are along axes of measurement (right, left femoral axes, dorsal line of tegmen). Background grid, woven metal screening $=3$ squares per $\mathrm{cm}$. Amplitude of oscillotrace $=50 \mathrm{mV} / \mathrm{cm}$, square wave $=\mathrm{I} / 2 \mathrm{~cm}$.

Fig. 9, line at left illustrates the calculated synchrony of the audio oscillotrace with the open shutter of the objective system (shutter speed is 0.5 msec duration).

Fig. 11 to 13, note regularity of oscillotrace as left femur begins downstroke first and then the sonic (and perhaps mechanical) interference as the right femur begins the downstroke, the femoro-tibial angle is kept closed throughout. Fig. 22 shows probable sonic amplification as the femora move into phase. Finally, as left femur stops moving (Fig. 39), the sound of the right femur approximates the regular wave form and amplitude of Figs. 11 to 13 . Refer to Fig. 44 for angle measurements and time relationships of the entire motion. 


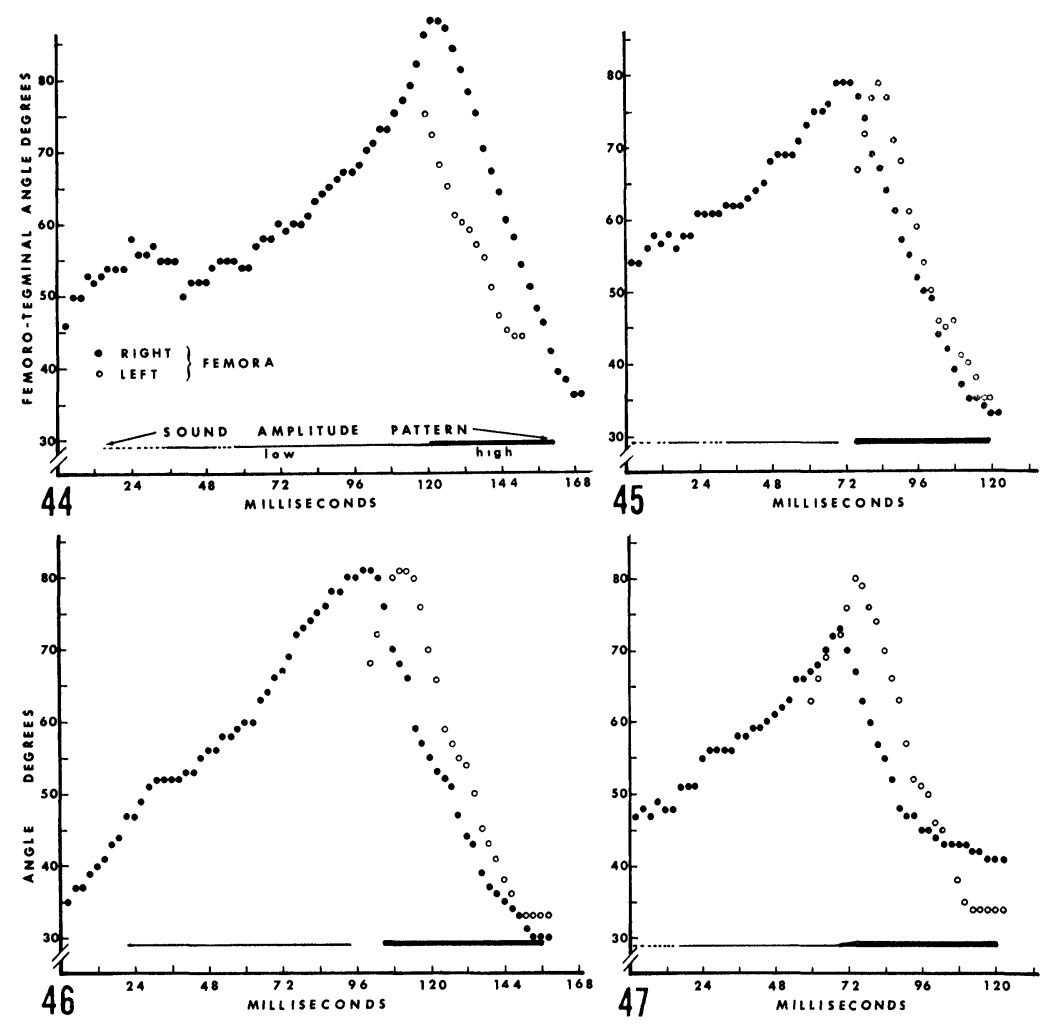

Fig. 44 through 47 . Graphs of four unitary stridulations in lateral view during an interaction between two males, one attempting courtship (illustrated, the other responding with the male interaction "rasp" or "femurshake with wing-striking" (not illustrated). The frames of Fig. 44 are partly reproduced in Figs. $8-43$ and the angles relative to the tegminal dorsal line are drawn in Fig. 8. Alternate frames were measured, the abscissa points are frame numbers converted to msec. The far (left) femur could only be measured when out of synchrony with the near (right) femur, i. e., on the downstroke. Note: a) either femur can lead on the downstroke, lagging behind the other by 20 to $30^{\circ}$ and 12 to $24 \mathrm{msec}$; b) high amplitude sound occurs only on the downstroke; and c) total silence occurs if both femora pass one another at angles above $70^{\circ}$ (see Fig. 48), but if one femur fails to complete the full upstroke, the sound is not interrupted. 
phase shift of right and left hind femora. In these grasshoppers which produce several clearly defined amplitude-modulated (AM) pulses per stroke by each femur, phase shift serves to blur or erase the amplitude-modulation which each femur alone is producing. His careful analysis shows, however, that this AM-erasure is due not to a sloppy coordination of the two femora, but rather that the proprioceptors of the two legs produce a feedback which precisely times the movements to the msec. He postulates that the main signal is a frequency modulated (FM) pulse series superimposed on the combined $A M$ system, ranging between $250 \mathrm{~Hz}$ to $8 \mathrm{KHz}$. Elsner suggests that there may be discrete frequencies in this range which would activate specific groups of sensory cells or neuronal circuits in a manner already known in locusts. If we reexamine Figs. 8-43 of the present paper, even the single AM-pulsed chirp of Arphia sulphurea has a rather regular, though weak, FM signal which peaks several times at about $\mathrm{IO} \mathrm{KHz}$ in addition to the carrier frequency of about $5 \mathrm{KHz}$ (average). This $\mathrm{FM}$ signal would appear in a sonagram as a faint octave overtone merging with the instrumental artifact (see Willey \& Willey, 1969), perhaps indistinguishably. Nevertheless, one of the earliest determinations of an insect's acoustic sensitivity was performed on A. sulphurea by Wever (1935) who showed that the maximum sensitivity of the tympanal organ was reached at Io $\mathrm{KHz}$ - a result which makes the oscillographically observed FM signal more biologically significant.

I present the following hypothesis: that the necessity to place the femora out of phase, because the femoro-tibial joints overlap the midline, also allowed a metachronous mechanism to develop which could control the frequency modulation of the signal. Arphia sulphurea and other oedipodines are at the least modified end of the spectrum and show perhaps how the more elaborate gomphocerine signal systems began.

\section{Technique Recommendations}

The technique of superimposing synchronizable, visually transduced signals on a high-speed film of a moving structure is elegant, but expensive. However, good preparations are permanent and can be analyzed over and over for new permutations. I advise one to copy the best sections by means of an internegative, before they are viewed in a standard projector or motion analyzer. A careful check through a clean $16 \mathrm{~mm}$ movie editor is the maximum handling the original should receive. Then the original should be filed away 
using proper film storage procedures, a positive made from the internegative and then the internegative should be filed. Analysis should be conducted with the positive - if possible one should pay extra to get an "answer print" in which very little of the original resolution is lost. Insist on the processor's retaining the side numbering of the original; every twentieth frame is numbered in sequence, a very useful reference for frame-by-frame analysis. A professional movie processor will advise customers on special applications, including A \& B answer prints for an exhibit, film titling and/or optical vs. magnetic sound track.

Improved techniques of filming could include I) use of high intensity strobe lights flashing at a rate synchronized by the shutterpulse signal of the camera and at a speed higher than the flickerfusion frequency of the insect's eyes. This would reduce the heat generated, but on the other hand there seems to be an upper limit to the frequency of stroboscopic flashing and resulting light intensity which allows the insects so far examined to behave normally. Other improvements in technique would include 2) a system allowing easy attachment of a mini-oscilloscope to the camera, thereby allowing easy movement of the camera relative to those of the subjects. A less expensive dual-trace mini-CRO is on the market (Tektronix 212) and is quite satisfactory for speeds up to 2000 pps. Also 3) use of reflective paints at anatomical points of reference, and 4) combination with some other techniques now in use, including telementry (especially magnetometers with Hall-generators), probe microphones, electrode pickups, etc. superimposed and synchronized on the film frame.

The versatility and precision of ptenocinematography with synchronized oscillography for analysis of animal behavior is not equalled by any other method and, as one becomes familiar with the technique, the expense of film will decrease. The maximum initial investment and maintenance are probably equal to that of the least expensive electron microscope, if one needs to purchase an audiometric room and all ancillary facilities.

This technique is most useful for biomechanical studies where precise synchronization and micro-timing is necessary, i.e., where movements take less than $50 \mathrm{msec}$, as in the vibratory stridulations of many grasshoppers (Otte, I970; Willey \& Willey, 1969). Otherwise, videotape systems can approximate a 60 pps cinema system and, combined with simultaneous or ex post facto oscillography of the recorded sounds (Wussow et al., 1974; Steinberg \& Willey, 1974), would be as useful and less expensive. 


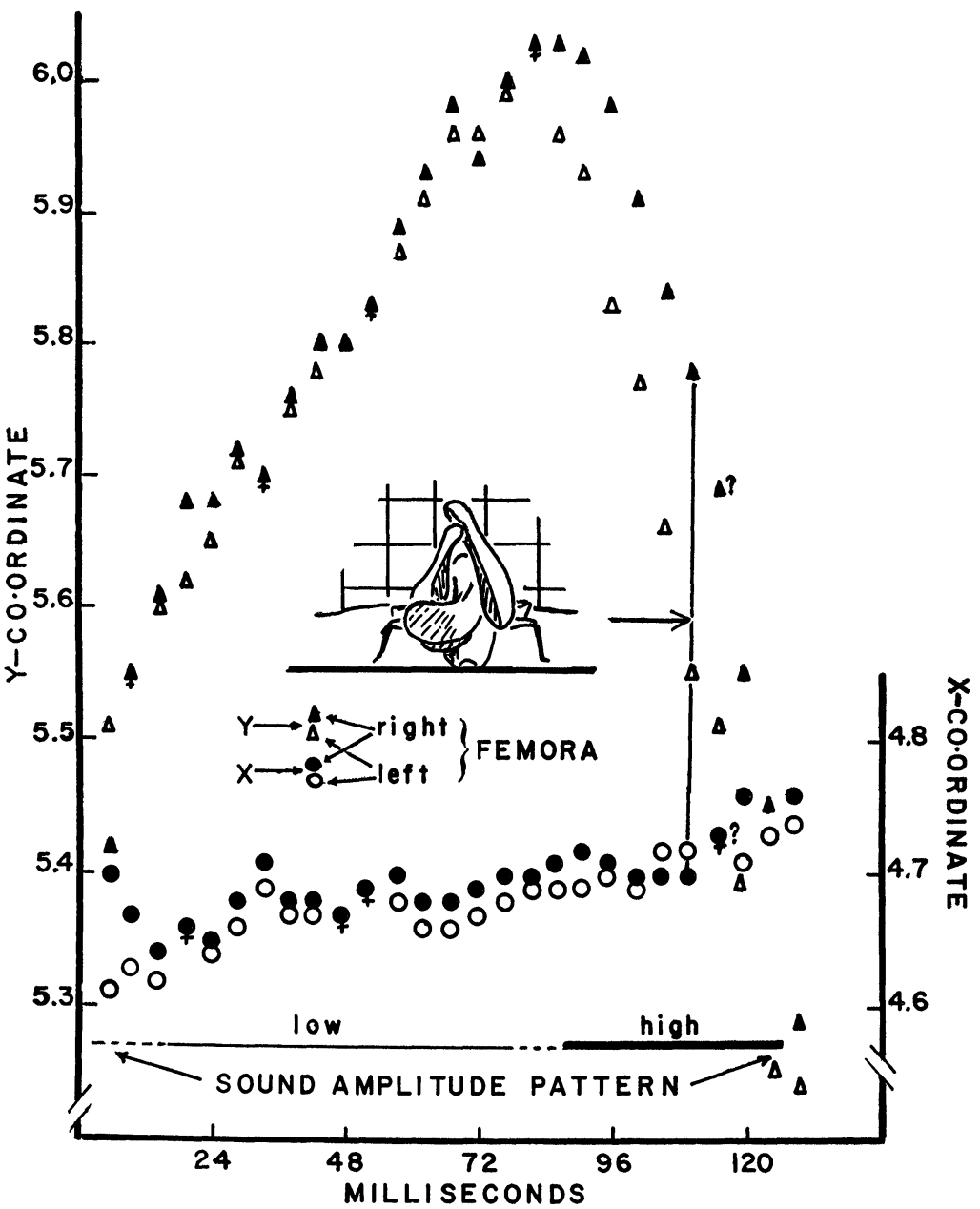

Fig. 48. Posterior view of stridulation movement made while male turns around in cage, pressing the wing-tips against the glass (insert). $X$ and $Y$ coordinates of the medial points of the femoro-tibial joints were measured instead of angles which could not be discerned readily. Angle of view is about $10^{\circ}$ from the horizontal. Y-coordinates ( + triangle) approaching unity cr overlapping represent parallel motion in the plane of the stroke, $X$-coordinates approaching unity or overlapping represent convergent motion at right angles to the plane of rotation, i.e., toward the midline. Note that the greatest $\mathrm{Y}$-separation of the two femoral tips coincides with convergence in the $\mathrm{X}$-dimension, $\mathbf{i}$. e., the femoral tips overlap the midline and must displace one another if any pressure is to be placed on the tegminal file, imposing the asynchrony of downward motion observed in Figs. 44-47. 


\section{Conclusions}

Analysis of micromovements during insect communication is crucial to understanding the external effects of internal neuromuscular systems and would be a desirable part of electrode implantation experiments as those performed by Elsner \& Huber (1973) and Elsner (1974b). In addition, the comparative behavioral analysis is much enhanced if the motion is precisely linked with the signal presented. As Walker et al. (I970) have pointed out and demonstrated (Walker \& Dew, 1972), if the motions are similar and produced by the same neuromuscular mechanisms (but the acoustic signals differ between taxa) then those taxa probably have some common lineage. I think this may be truer of insects which call to prospective mates from hidden positions than the Oedipodinae which seem to have a system of visual semaphores (colored hindfemora, tibiae, and/or abdomens) presented simultaneously with the acoustic signals in close visual communication (Willey \& Willey, 1969). Thus careful analysis of oedipodine signals may reveal as Otte $(1970,1972)$ and Steinberg \& Willey (1974) indicate that the acoustic signals often are a lingua franca among closely related as well as relatively unrelated taxa, advertising sex, physiological state, and "mood". Motion or color variation may be the species-specific component. We are not yet in a position to postulate rules of phylogeny as far as the oedipodine grasshoppers are concerned.

\section{SUMMARY}

The unitary stridulation (chirp) of a band-winged grasshopper species has been analyzed by ultra-high-speed motion photography (ptenocinematography), audiospectrography, and scanning electron microscopy. By means of a two-lens system, oscillographic traces of the sounds were synchronized with a motion picture of these sounds at $0.5 \mathrm{msec}$ per picture. This was sufficient to determine that the downstroke of the hind femora, pressing against the tegminal stridulatory file, produced the definitive signal previously recorded audiospectrographically and oscillographically by other authors. The oscillographic spike frequency was proved to be at a $\mathrm{I}: \mathrm{I}$ ratio with the number of pegs struck by the femoral scraper. The right and left hind femora move in synchrony on the upstroke and produce a very weak and irregular series of acoustical spikes; however the two femora pass out of phase to produce the high amplitude and higher velocity downstroke $(>4650 \mathrm{~Hz}$ per femur). Mechanically, this 
phase shift is caused by the necessity of the femoro-tibial joints to overlap the mid-point of the dorsum in order to produce enough pressure on the file. Functionally, it is postulated that this system produces a frequency modulation which allows an FM signal of $\cong$ ro $\mathrm{KHz}$ to be pulsed periodically during the downstroke - a frequency long ago proved to be also at the greatest sensitivity of the tympanal receptor of this species.

\section{ACKNowledgements}

I thank Howard Johnson (Visual Data Systems, Inc.) and Prof. Walter Bock (Columbia University) for their help and encouragement, and Gerry Temaner (University of Illinois Office of Instructional Resources) for his suggestions about proper duplication of valuable original sequences. Ronald Weibel was the technologist for the scanning electron microscope study and Ronald Walkosz, David Mucha and Dr. R. L. Willey helped prepare the plates for publication. Joan Bieler, Allan Johnson, Mrs. June Steinberg and Luis Jiminez helped in the recording of measurements. David Ballestas and Luis Jiminez (Federal Work-Study Program) cared for the cultures. This study was supported partly by grants from the University of Illinois Research Board and the Department of Biological Sciences by the kindnesses of Professors J. O. Corliss and E. B. Hadley, former Department Heads. Publication was aided by an NSF grant GB-35594 to RBW.

\section{Literature Cited}

BAILEY, W. J.

1970. The mechanics of stridulation in bush crickets (Tettigonioidea, Orthoptera). I. The tegminal generator. J. Exp. Biol., 52: 495506.

Bailey, W. J. and W. B. Broughton

1970. The mechanics of stridulation in bush crickets (Tettigonioidea, Orthoptera). II. Conditions for resonance in the tegminal generator. J. Exp. Biol., 52: 507-518.

ELSNER, N.

1970. Die Registrierung der Stridulationsbewegungen bei der Feldheuschrecke Chorthippus mollis mit Hilfe von Hallgeneratoren. $Z$. vergl. Physiol., 68 : 417-428.

1974a. Neuroethology of sound production in gomphocerine grasshoppers (Orthoptera: Acrididae). I. Song patterns and stridulatory movements. J. Comp. Physiol., 88: 67-102.

1974b. Neural economy: bifunctional muscles and common central pattern elements in leg and wing stridulation of the grasshopper Stenobothrus rubicundus Germ. (Orthoptera: Acrididae). J. Comp. Physiol., 89: 227-236. 
ELsNer, N. ANd F. Huber

1973. Neurale Grundlagen artspezifischer Kommunication bei Orthopteren. Fortschr. Zool., 22 : 1-48.

Morris, G. K. and R. E. Pipher

1972. The relation of song structure to tegminal movement in Metrioptera sphagnorum (Orth., Tettigoniidae). Can. Entomol., 104: 977-985.

OTTE, D.

1970. A comparative study of communication in grasshoppers. Misc. Publ., Mus. Zool., Univ. Michigan, 149: 1-168.

Pasquinelly, F. and M.-C. Busnel

1955. Études préliminaires sur les méchanismes de la production des sons par les orthoptères. In Busnel, R.-G., L'Acoustique des Orthoptères. Ann. Epiphyt., Fasc. Spécial: 145-153.

Pierce, G. W.

1948. The Songs of Insects (Cambridge: Harvard Univ. Press), 329 pp.

Steinberg, J. B. ANd R. B. Wil.Ley

1974. Visual and acoustical social displays by the grasshopper Chortophaga viridifasciata (Acrididae: Oedipodinae). Can. J. Zool., 52: 1145-1154.

Verheijen, F. J.

1958. The mechanisms of the trapping effect of artificial light sources upon animals. Arch. Neerl. Zool., 13 : 1-107.

Walker, T. J., J. F. Brant, and D. Dew

1970. Sound-synchronized, ultra-high-speed photography: a method for studying stridulation in crickets and katydids (Orthoptera). Ann. Entom. Soc. Amer., 63 : 910-912.

WaLker, T. J. AND D. DeW

1972. Wing movements of calling katydids: Fiddling finesse. Science, 178: 174-176 ( + cover).

Wever, E. G.

1935. A study of hearing in the sulfur-winged grasshopper (Arphia sulphurea). J. Comp. Psychol., 20: 17-20.

WILley, R. B.

1971. Slowed motion studies of sound production in insects. Proc. Entom. Soc. Amer., North-Central Branch, 26: 78 (abstr.).

WiLley, R. B. ANd R. L. Willey

1969. Visual and acoustical social displays by the grasshopper Arphia conspersa (Orthoptera: Acrididae). Psyche J. Entom., 76: 280305.

Wussow, P. A., R. B. Willey And J. B. Steinberg

1974. Synchronous visualization of video-taped sounds and motions in insects. Psyche J. Entom., 81: 209-217. 

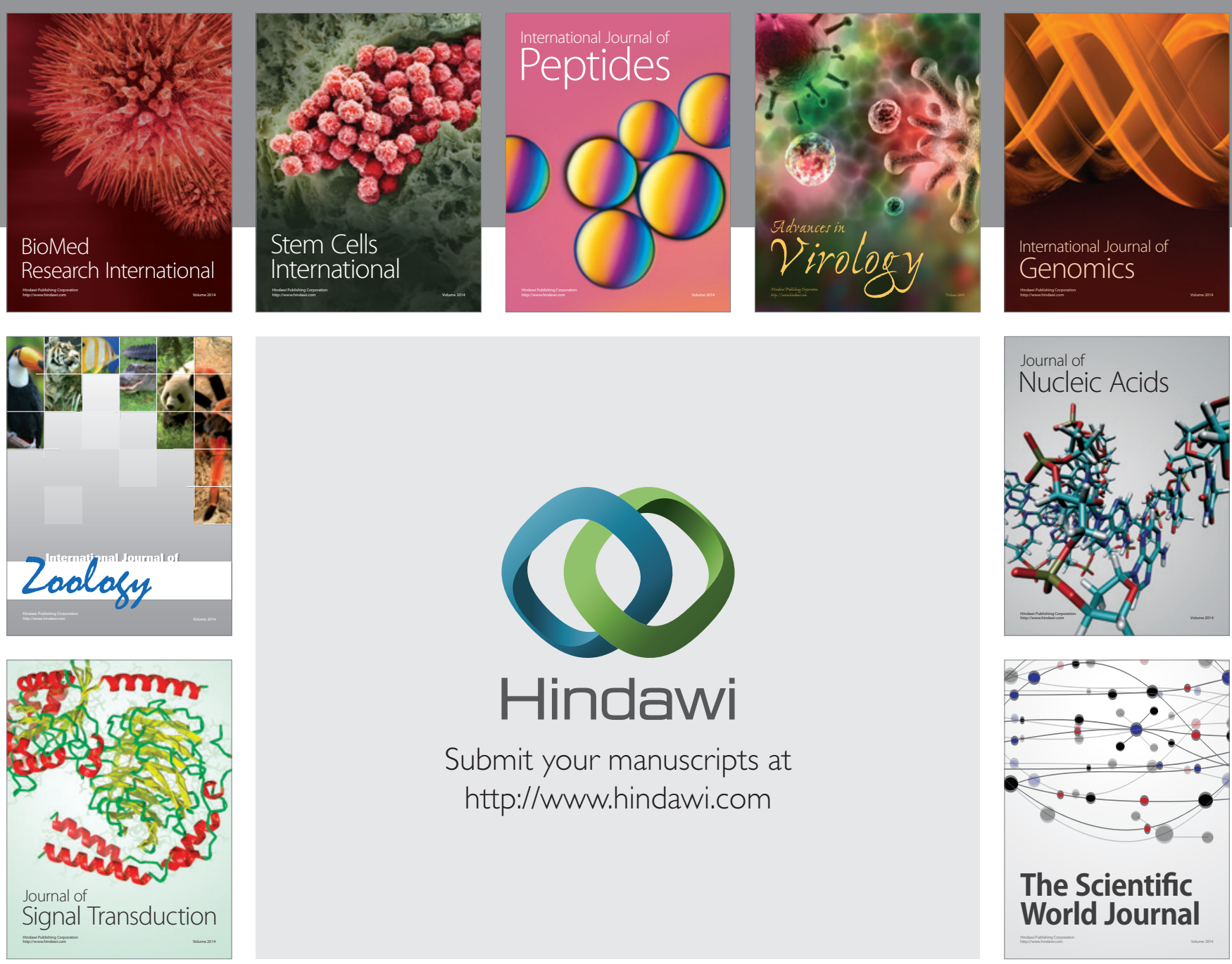

Submit your manuscripts at

http://www.hindawi.com
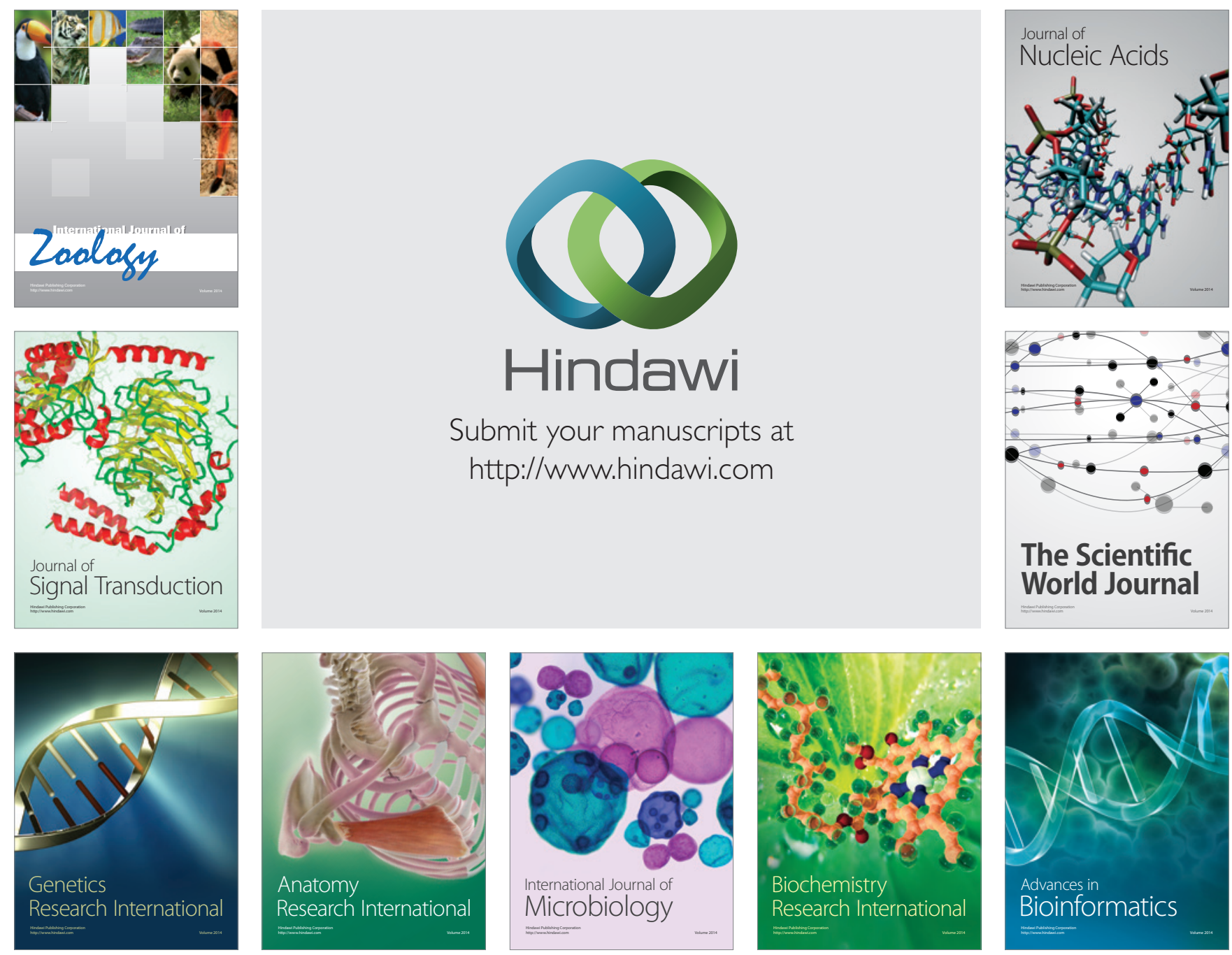

The Scientific World Journal
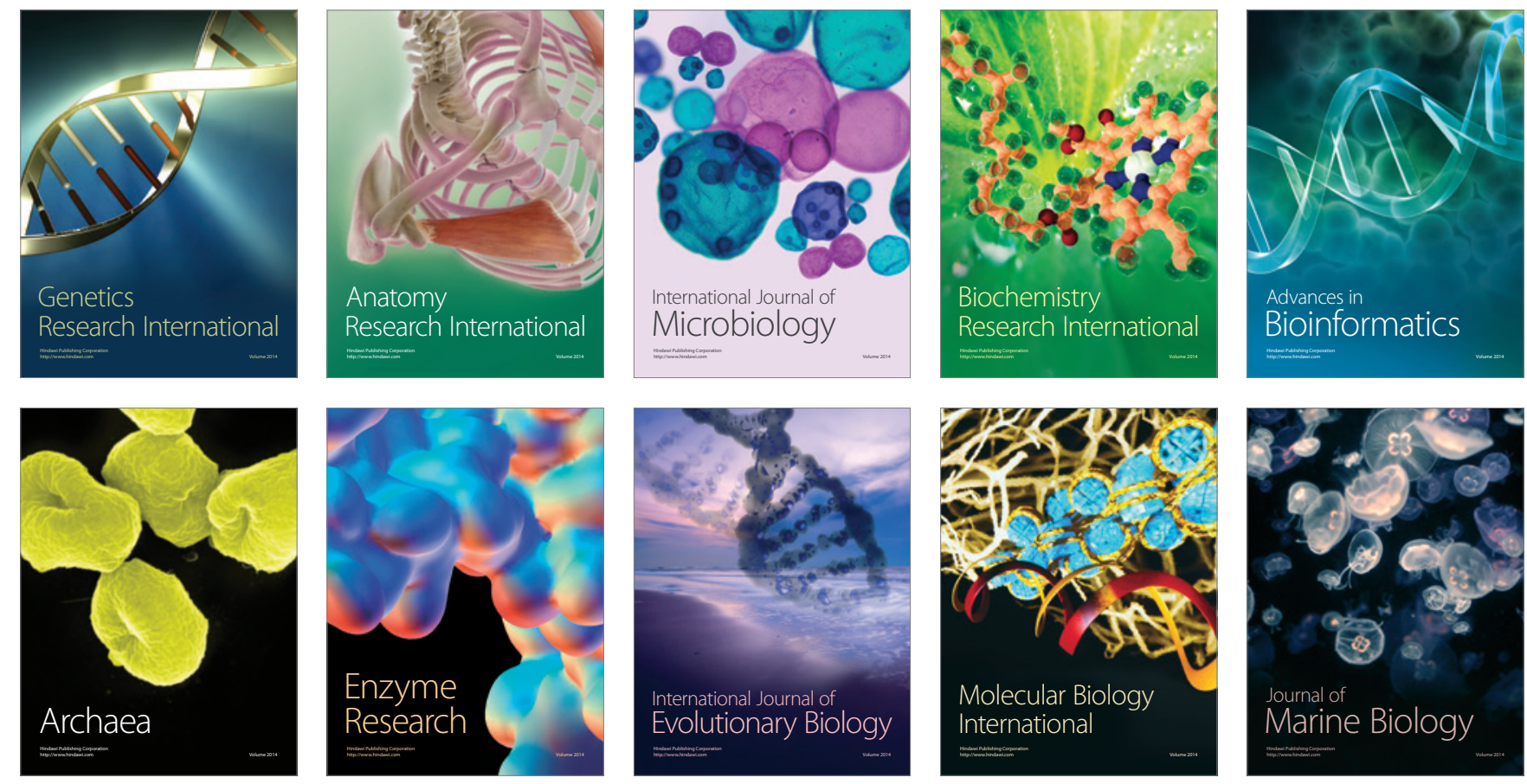